\title{
Undesirable Implications of Disclosing Individual Genetic Results to Research Participants
}

Leslie A. Meltzer, Georgetown University Law Center and Johns Hopkins Bloomberg School of Public Health

Ravitsky and Wilfond (2006) correctly highlight the need for uniform guidelines to assist investigators and institutional review boards (IRBs) in determining whether to disclose individual genetic results to research participants. However, their results-evaluation framework, like other proposals that call for the disclosure of individual results to research participants (Partridge and Winer 2002; Rothstein 2006; Shalowitz and Miller 2005), is troublesome for two related reasons. First, their justification for disclosure rests on the mistaken view that principles of beneficence, respect, reciprocity, and/or justice ethically require researchers to offer participants individual genetic results. Whereas these principles and others obligate physicians to share individually relevant results with patients in the clinical care setting, they do not similarly obligate investigators to share such information with participants in the research setting. Second, because Ravitsky and Wilfond's proposal conflates the aims of clinical research with those of clinical care, participants may suffer from a therapeutic or diagnostic misconception (Clayton and Ross 2006), researchers may be inclined to overstate the benefits of enrollment, and institutional review boards (IRBs) may face unforeseen difficulties in assessing trial risks and benefits.

Beneficence, respect for persons, reciprocity, and justice are important components of ethical research, but none of these principles are violated or diminished when investigators do not share individual genetic results from research. Beneficence requires investigators to maximize possible benefits to participants and society at large while minimizing possible harms. Whether a clinical trial meets the requirement of beneficence is determined ab initio by an IRB before any participants are enrolled. At this stage of review, an IRB cannot weigh the possibility that some participants may gain individually useful results from participation. There is no guarantee that any given trial will produce such results. In contrast, if a study does generate individual information, it may apply only to participants with certain genomic characteristics. And even in this case it is not possible to determine whether a given participant will perceive the information as a benefit or harm once confronted with it. Because a clinical trial must meet the requirements of beneficence regardless of whether it returns individual research results, it cannot be the case that beneficence requires investigators to offer results.
Ravitsky and Wilfond (2006) may respond that failure to disclose genetic information that is of direct clinical utility to participants violates nonmaleficence, the duty to minimize harms in research. However, except in the very rare circumstance in which failure to disclose individual genetic information to a participant poses a certain and near-immediate threat to morbidity (and thus should be disclosed), nonmaleficence does not trigger disclosure. Investigators have a duty not to expose participants to undue risk. This negative duty of nonmaleficence is quite different, however, from any positive duty to promote participants' interests, the activity that seems to motivate Ravitsky and Wilfond's proposal. They may reply that failure to offer beneficial results is itself a harm, but this understanding of harm as "failure to benefit" would, as previously noted, pose intractable difficulties for IRBs assessing probable harmbenefit ratios for research trials (Parker 2006).

Ravitsky and Wilfond's (2006) argument that respect for persons requires disclosure is similarly mislaid. Respecting participants means treating human beings capable of self-determination as autonomous agents. It requires researchers to present prospective participants with adequate information about a trial, to honor their voluntary decision about enrollment, and to accept participants' decisions to withdraw from trials should they so choose. But respect for persons does not require researchers to account for participant interests or preferences about disclosure of individual genetic research results when designing a study. Investigators best respect participants as persons when they disclose the terms of the research and allow people to choose whether to enroll. This approach, rather than integrating participant preferences into research, is what The Belmont Report and the Common Rule mean by respecting participant selfdetermination.

Just what Ravitsky and Wilfond (2006) envision when they claim that reciprocity in research requires disclosure is somewhat unclear. They contend that reciprocity requires researchers to consider the nature of their relationship with participants when deciding to disclose results, paying particular attention to "the duration and the intensity of this relationship" $(2006,8)$. This approach to reciprocity is somewhat more nuanced than the standard call for participants to receive something from researchers in exchange for participation. If researchers were to disclose individual results to participants, then arguably the degree 
and nature of their relationship with participants should factor into any decision about disclosure. But from the standpoint of reciprocity, if participants receive anything in exchange for participation (such as monetary compensation or aggregate study results), they all ought to receive the same thing regardless of the duration or intensity of their relationship with researchers, and they ought to receive it regardless of the trial's success. In the case of disclosing individual genetic results, however, the compensation is both uncertain and unlikely to be available to all participants.

The final principle that Ravitsky and Wilfond (2006) employ is justice. They argue that "justice requires balancing participants' preferences against considerations of prioritizing resources utilization in order to maximize the benefits of research to society" (8). As I understand it, this statement is less a justification for disclosing individual results to participants than it is a recognition that doing so may cause complicated trade-offs with other research priorities. They do not contend that failing to disclose individual results violates justice per se, only that once we enter the realm of disclosure, there are complex issues of resource allocation. On this point, I agree. The resultsevaluation approach creates the very real possibility that research participants in studies with larger budgets are more likely to receive results than those in studies with less room for such expenditures. Even within trials, it may become difficult to treat participants equally over the duration of the study.

Ravitsky and Wilfond's (2006) justifications for their approach suggest that they have fallen prey to the same problem that plagues the autonomy-based approach: the failure to distinguish between medical practice and clinical research. In the personal context of the physicianpatient relationship, fundamental ethical principles compel physicians to share individual genetic results with patients. In fact, failure to share such information in all but the most exceptional circumstances is legally actionable because physicians are fiduciaries to their patients. This means that physicians have not only an ethical, but also a legal duty to act solely for the benefit of their patients (Morreim 2005).

In contrast, in the research setting, investigators are not fiduciaries of participants. Their primary goal is not, and indeed cannot be, to benefit any one participant. The very distinction between research and clinical care rests on the fact that research aims to produce generalizable knowledge for society at large, whereas clinical care aims to meet individuals' specific needs, interests, and preferences. This distinction does not mean that participants in clinical trials gain no benefits from participation. Participants may, for example, receive better care than they would receive outside a trial or gain access to otherwise unaffordable medication. But the nature of research design-from randomization to double blinding-betrays its overarching purpose: to yield scientifically accurate, generalizable knowledge.

Ravitsky and Wilfond's (2006) proposal breaks down this important distinction between medical care and research by conflating the duties owed to patients with those owed to participants. In addition to the rationale outlined previously, there are two further reasons we should resist this move. First, offering individualized information to research participants invites them, as well as researchers and IRBs, into the therapeutic misconception, or what Clayton and Ross (2006) term the "diagnostic misperception." Both terms capture the expectation that, under Ravitsky and Wilfond's proposal, participants will receive clinically relevant personal information just as they would in a physicianpatient relationship. This view is pernicious because people who otherwise would not enroll in research may choose to do so in the hope of personal benefit, and researchers may be inclined to overstate the benefits of participation. Moreover, as discussed previously, IRBs may find it difficult to conduct a valid risk-benefit assessment of proposed research.

The second reason for maintaining a dichotomy between clinical research and medical practice is to protect research from the intrusion of unnecessary malpractice litigation. Investigators are not fiduciaries of research participants, and as such, do not presently have a legal obligation to act in the best interests of participants (Morreim 2005). If, however, researchers have an ethical duty to disclose individual research results, as Ravitsky and Wilfond (2006) contend they do, then a court may be able to conclude that investigators owe participants fiduciary duties. In the abstract, this conclusion may seem like a matter of semantics, but if researchers become participant fiduciaries, their ability to conduct research as we know it may drastically change.

\section{REFERENCES}

Clayton, E. W., and L. F. Ross. 2006. Implications of disclosing individual results of clinical research. Journal of the American Medical Association 295(1):37.

Federal Policy for the Protection of Human Research Subjects, 45 C.F.R. 46 (Department of Health and Human Services, January 16, 1981); 21 C.F.R. 50, 56 (Food and Drug Administration, January 27, 1981).

Morreim, E. H. 2005. The clinical investigator as fiduciary: discarding a misguided idea. Journal of Law, Medicine \& Ethics 33(3):586-599.

The National Commission for the Protection of Human Subjects of Biomedical and Behavioral Research. The Belmont Report: Ethical Principles and Guidelines for the Protection of Human 
Subjects of Research. Washington, D.C.: Department of Health, Education and Welfare, 1979.

Parker, L. S. 2006. Rethinking respect for persons enrolled in research. ASBH Exchange 9(2):1, 6-7.

Partridge, A. H., and E. P. Winer. 2002. Informing clinical trial participants about study results. Journal of the American Medical Association 288(3):363-365.

Ravitsky, V., and B. S. Wilfond. 2006. Disclosing individual genetic results to research participants. American Journal of Bioethics 6(6): 8-17.
Rothstein, M. A. 2006. Tiered disclosure options promote the autonomy and well-being of research subjects. American Journal of Bioethics 6(6):20-21.

Shalowitz, D. I., and F. G. Miller. 2005. Disclosing individual results of clinical research: Implications for respect for participants. Journal of the American Medical Association 294(6):737-740.

Copyright (C) Taylor \& Francis Group, LLC

DOI: $10.1080 / 15265160600935811$

\section{Disclosing Genetic Research Results: Examples from Practice}

Kelly E. Ormond, Northwestern University

Using examples from my own practice as a genetic counselor, I would like to provide a context for how the points raised by Ravitsky and Wilfond (2006) and other peer commentators can be, and are, practically incorporated into the practice of medical genetics. I applaud the authors for their initiative to develop an objective approach that considers analytic and clinical utility, clinical validity, personal meaning, and the relationship with investigators; this approach is critical because the typical defaults of disclosing results to all or none or allowing institutional review board (IRB) discretion for disclosure lead to inconsistent approaches that minimize opportunities for participant autonomy and values-based decisions about genetic research results.

Although genetic testing is frequently discussed, it is currently only available for approximately 1300 genetic conditions; approximately $25 \%$ of those conditions have only research genetic testing as an option (www.geneclinics.org). In the early stages of genetic testing research, affected individuals and their families may be recruited into research to identify genes that contribute to a disease state. Once the causal gene(s) is identified, it may still take years to translate from research to clinical testing; this process is even more difficult for rare disorders for which laboratories may not wish to invest time or resources to offer clinical testing. In practice, this time line means that research genetic testing may be performed for essentially clinical purposes. When clinical testing is not yet available, families may believe that research based genetic testing is the "only option" and participate hoping researchers will identify the causal gene so that future testing will become available; however, they may also directly hope to gain information about the genetic makeup of affected family members. As a clinician who is often in the position of presenting research testing options to patients, I argue that, out of respect for subjects, their autonomy, and the potential impact on their personal welfare, researchers should offer to disclose research results to patients if one can obtain verifiable results to which participants assign personal value, particularly when the research setting is the only venue in which testing is available.

These situations are less ethically challenging than the scenarios in which genetic test results are obtained as a component of a larger study. A clear statement about intent to disclose results (or not) is an important part of the informed consent process. I have had healthy patients referred who participated in a research study for dementia that involved the assessment of apolipoprotein status and who desired to learn their genetic results. I have also worked with families who are contemplating genetic research to help identify a cause for dementia in deceased relatives, with the intent that predictive testing could be made available to other yet unaffected family members if results were provided. Here, medical management would not be altered, but families still reported high value in learning the genetic information.

When helping families and patients consider the risks and benefits of obtaining genetic test results, the "accuracy" of test results and the level of certainty about what that will mean for them and their family are important. 
Copyright of American Journal of Bioethics is the property of Routledge and its content may not be copied or emailed to multiple sites or posted to a listserv without the copyright holder's express written permission. However, users may print, download, or email articles for individual use. 